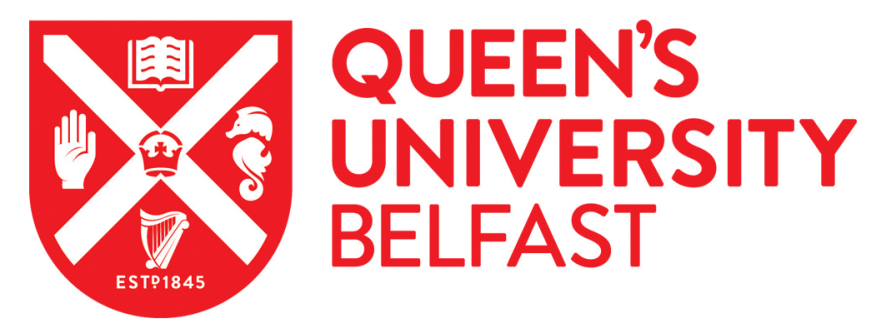

\title{
Social isolation and older men - learning from research
}

Devine, P., Montgomery, L., Anand, J., \& Ní Dhónaill, C. (2019). Social isolation and older men - learning from research. Community Development Journal, 54(2), 273-289. https://doi.org/10.1093/cdj/bsx021

\author{
Published in: \\ Community Development Journal
}

Document Version:

Peer reviewed version

Queen's University Belfast - Research Portal:

Link to publication record in Queen's University Belfast Research Portal

\section{Publisher rights}

(c) Oxford University Press and Community Development Journal 2017. This work is made available online in accordance with the publisher's policies. Please refer to any applicable terms of use of the publisher.

\section{General rights}

Copyright for the publications made accessible via the Queen's University Belfast Research Portal is retained by the author(s) and / or other copyright owners and it is a condition of accessing these publications that users recognise and abide by the legal requirements associated with these rights.

Take down policy

The Research Portal is Queen's institutional repository that provides access to Queen's research output. Every effort has been made to ensure that content in the Research Portal does not infringe any person's rights, or applicable UK laws. If you discover content in the Research Portal that you believe breaches copyright or violates any law, please contact openaccess@qub.ac.uk. 


\section{Social isolation and older men - learning from research}

\section{Corresponding author:}

Paula Devine

p.devine@qub.ac.uk

Lorna Montgomery

Janet Carter Anand

Caoimhe Ní Dhónaill

Paula Devine is Coordinator of the ARK Ageing Programme, and is based in Queen's University Belfast. She also coordinates the Northern Ireland Life and Times Survey. Her research interests are masculinity, men's health, public attitudes, and the dissemination of social science knowledge.

Lorna Montgomery is a lecturer in Social Work at Queen's University, Belfast. Prior to taking on this role, she practiced as a social worker in the areas of mental health and adult protection. Her teaching and research interests include adult safeguarding, cross cultural interventions and bereavement care.

Janet Carter Anand is a Professor of International Social Work, Department of Social Sciences, University of Eastern Finland. She has lectured, researched and published on the topic of social gerontology in Australia, Republic of Ireland, United Kingdom and Finland.

Caoimhe Ní Dhónaill received her PhD in 'Perceptions of Ageing in Zambia and Northern Ireland' from Queen's University, Belfast. Her main research focuses include ageing, isolation, gender and loneliness. 
Social isolation and older men - learning from research

Word count 6985

\begin{abstract}
Due to an increase in life expectancy and other demographic factors, there is now a larger number of older men and women in our society. At the same time, loneliness and social isolation are increasing. This article draws upon a research project undertaken in 2014 to explore existing services for socially-isolated older men in Belfast, and outlines key messages. Firstly, the paper highlights some of the experiences of isolated older men in one region of the UK. Secondly, it provides a review of service provision, providing 'expert' knowledge about how these services can affect men's lives in different ways. Finally, the paper offers recommendations for enhancing the provision of services for socially-isolated older men, based on the information gathered throughout the project.
\end{abstract}




\section{Introduction}

This article draws upon a research project undertaken in 2014 to explore existing services for socially-isolated older men in Belfast. While the rationale and methods of the project are outlined, the main focus of the paper is to discuss the key messages that emerged from the research relevant to work with older men in a community setting within the post-conflict context of Northern Ireland. Some comment is also made on the value of professionalised services in the context of community development approaches.

As in other regions, Northern Ireland $(\mathrm{NI})$ is experiencing demographic change, one driver of which is the increase in life expectancy. Between 1990 and 2015, the percentage of the $\mathrm{NI}$ population aged 65 and over grew from $12.8 \%$ to $15.8 \%$, which represents an increase of approximately 86,000 people. Moreover, not only is the general population ageing, but there has been progressive ageing of the older population itself (ONS, 2015). Importantly, has not happened symmetrically for men and women. Women have historically lived longer than men, although this gap has reduced from 5.96 years in 1991-1993 to 4.3 years in 2011-13. This faster improvement in male mortality may be largely due to reduction of smoking levels for men, as well as advances in health treatments for circulatory illnesses. In addition, traditional 'male' occupations have become less physical and safer (ONS, 2014). In Northern Ireland, this has resulted in a $75 \%$ increase in the number of men aged 75 and over between 1990 and 2015, compared with $33 \%$ for women.

Living alone is a feature of many people's lives, with $22 \%$ of men aged 65 or over in England and Wales in 2011 living alone. This figure increased to $41 \%$ for men aged 85 or over (ONS, 2013). The increasing number of older men means that these figures are likely to rise, and it is anticipated that loneliness and social isolation will also be set to grow (Beach and Bamford, 2014). Consequently, later life is becoming less numerically dominated by women (Arber, Davidson and Ginn, 2003). In other words, older men are more visible statistically, and importantly, are more visible within our communities. Thus, it is important that how and why older men's experiences of old age differ from that of women is understood, and how our society needs to respond. This paper provides a review of service provision, using 'expert' knowledge about how these services can affect men's lives in different ways and offers recommendations for enhancing the provision of services for socially-isolated older men. As well as an instrumental focus on service development, however, the paper highlights how older men have been missing from research and service delivery. This is important within community development, given its focus on self-determination and social justice for marginalised groups (Emejulu, 2011). Arguably, 'older men' comprise one such group.

Importantly, any study of community provision in Northern Ireland should consider the exceptional nature of this society. The history of over 30 years of civil conflict is well documented. For example, since 1968, over 3,500 people were killed, comprising 3,279 males and 322 females (Fay et al., 1999). Since the ceasefire of 1994, the intensity and character of sectarian conflict has changed. Nevertheless, there remains a strong political divide between communities, and residential migration remains high, especially within social housing (Murray and Murtagh, 2003). While there has been some decrease in residential segregation over the past 10 years, this may be, in part, due to international immigration (Shuttleworth and Lloyd, 2013).

\section{Loneliness and social isolation}

Despite the 'good news' story of greater life expectancy, loneliness and social isolation have been identified as key issues for older people: they can be a major cause of unhappiness and can contribute to depression and other mental health problems, as well as having an impact 
on physical health (SCIE, 2012). Whilst the terms 'loneliness' and 'social isolation' are often used as synonyms, they do not mean the same thing. Burholt (2011) describes loneliness as a subjective measure of unwelcome feelings or perceptions that are associated with a lack of contact with other people. Social isolation is a more objective concept, comprising a continuum ranging from absence of contact with other people (social isolation) to high levels of social contact or participation. Older people are particularly vulnerable to both loneliness and social isolation as a result of the loss of friends and family, mobility or income (SCIE, 2012).

Analysis of the English Longitudinal Study of Ageing (ELSA) showed that 14\% of older men experienced moderate to high social isolation, compared with $11 \%$ of women. A higher proportion of men than women had contact with their children, family or friends less than once a month (Beach and Bamford, 2014). This is reflected in the finding that older men without partners were more socially isolated and lonely than older women with partners. Again, using ELSA data, Steptoe et al. (2013) found an association between social isolation and increased mortality. A similar relationship was also found between loneliness and mortality, although this was mostly accounted for by mental and physical health. Steptoe and colleagues conclude that although both isolation and loneliness diminish quality of life and well-being, attempts to reduce isolation would be more likely to have greater benefits in reducing mortality.

\section{Men's health and wellbeing}

Men's health is a growing concern internationally (Cordier and Wilson, 2013). Dillon and Butler (2011) highlighted that strong causal links exist between unemployment, recession and deteriorating economic circumstances; and the health and wellbeing of men. Courtenay (2000) discusses how leaving the occupational 'breadwinner' role, and the resulting loss of a community of co-workers can reduce a man's sense of his male identity. In addition, the taking on of a caring role for a partner with physical or mental disabilities is also a reality for many older men (Arber, Davidson and Ginn, 2003). As a result, social isolation, loneliness and depression are increasingly identified as major issues for men throughout the life course. In particular, men often have less involvement in support and friendship networks than women (Dalgard et al., 2006). Moreover, Eng et al. (2002) contend that less socially connected men are at a significantly increased risk of death by suicide, as well as from other causes. The groups most likely to lack social contacts with relatives, friends and neighbours are divorced and never-married older men (Ruxton, 2006). This lack of social networks renders these men more vulnerable to social isolation, which in turn, makes them less likely to receive the type of support that they might need to help them to remain living in the community if their circumstances change.

Emejulu (2011) discusses the problem of essentialist ideas of 'women' within feminist politics, which fail to take account of the intersection of other identities, such as race, class and age (Grimshaw, 2011). Arguably, the same is true of an essentialist idea of 'men'. Gender and age both intersect to influence social networks throughout the lifecourse, which in turn, have an effect on the benefits, and risks, of social participation (Thompson and Whearty, 2004). However, Calasanti (2004) contends that the suppression of emotions implicit in many forms of masculinity renders many men uncomfortable with the type of self-disclosure often involved in building up social networks.

Socio-demographic and socio-cultural changes over time have resulted in a larger variation of living arrangements than before, as well as more complex partner histories (de Jong Gierveld, 2003), which may have implications for the lives and relationships of older people. Arber, Davidson and Ginn (2003) highlighted the emotional support that older women who have 
been widowed may provide for each other. However, for widowed men there is often no equivalent support network. Increasing life expectancy and low remarriage rates mean that there is a growing proportion of older men who are living alone because they are divorced or never married. This is important, given that self-reported levels of loneliness may be related to the quality of relationship with a spouse or partner, suggesting that a relationship with a 'significant other' is of prime importance to men's well-being (ibid.).

Nevertheless, there is a danger of assessing the quantity and quality of social networks based on standards derived from a 'feminine ruler' in which the 'prescriptions for well-being' in later life derive from the experiences of the female majority (Davidson, Daly and Arber, 2003, p. 183). Rather, older men may wish to have a smaller, closer network of friends and acquaintances.

\section{Project methods and findings}

In 2014, the authors were commissioned to undertake a review of services for older men (aged 50+) within Belfast. The project sought: to review the extent and impact of current community, voluntary, statutory or private sector services which are aimed at combating social isolation among men in the Belfast area. The target group was men aged 50 years or over who have retired, or been unable to work through ill-health, and have become isolated.

The project team were supported by a key stakeholder group, in addition to a group of older men acting as peer researchers. A short synopsis of the methodology and key findings of the four stages of the project are provided below, with full details available in the project report (Devine, Carter Anand, Montgomery et al., 2014). This paper will privilege discussion of the findings of the qualitative components of the research (stages 2 and 4).

In stage one, a literature review explored different interventions used to address social isolation. The available evidence suggested that group work schemes were most effective, whilst one-to-one interventions were least effective. Community-level and structural issues, such as poor transport links, lack of opportunities for participation, poverty, and ageism also impacted social isolation (Buffel, Rémillard-Boilard and Phillipson, 2015).

In stage two, an audit of existing service provision in Belfast was undertaken. The extent, nature and accessibility of services provided by community, voluntary, statutory and private providers in Belfast, which target men aged 50 years or over with a specific focus on men who are tending to, or are socially isolated, was established. The audit indicated that there is a disproportionate number of services for and with men and women, compared to services which actively target men. The findings relating to the audit can be reviewed in the project report (Devine, Carter Anand, Montgomery et al., 2014).

Thirdly, ten interviews were carried out with purposively sampled older men aged 50 years or over who participated in a range of services across Belfast. These interviews provided 'expert' knowledge about how these services can affect men's lives in different ways. The pathways to, and reasons for, accessing these services varied. The benefits were similar: social contacts, friendship, an enduring sense of purpose in a post-work context, and consequent improvements to mental and physical health. The essential message was that feelings of usefulness are crucial in successful ageing for men.

Potential barriers to participation in these services include masculinity and pride, especially when seeking help. The most important means of recruiting men was word-of-mouth, although by definition, this will exclude those people who are most socially isolated. For 
some of the men, the legacy of the conflict in Northern Ireland remained central in their life. Whilst some services provide a place of tension; for others, they provided a place of potential reconciliation.

Finally, semi-structured interviews with six key commissioning and funding stakeholders explored the strategic context within which appropriate services are funded or provided within Belfast. No funder or provider identified a strategic focus on services for men in general, or older men in particular, although funders stated that they would finance services if particular needs were identified. The underrepresentation of men's groups was highlighted, both among the applicants to, and the grantees of, funding programmes. The lack of experience and capacity in relation to funding applications and governance was acknowledged as a problem. This has implications for the sustainability of services. Lack of knowledge of services remains an issue across sectors, and inhibits collaboration between service providers, and service uptake by users.

Similar findings were found by Beach and Bamford (2014), in their research of experiences of social isolation and loneliness among older men in England. Those authors highlighted that tackling isolation and loneliness necessitates multi-level action by individuals, organisations and government. Buffel and colleagues (2015) in their review of social isolation in Greater Manchester, highlighted ten characteristics of successful interventions to counter social isolation among older men and women: development within a theoretical framework; high quality approaches to selection, training and support of facilitators; involvement of older people as active participants of the planning, implementation and evaluation stages; emphasis of reciprocity in social support (meaning that participants are service recipients as well as support givers); utilisation of existing community resources and aim to build community capacity; offering social activity and support within a group format; including educational group programmes with a training element; targeting specific groups (such as a specified medical condition); developing interventions within an existing service; and undertaking process and outcome evaluations, and disseminating these findings.

\section{Recommendations}

Our research put forward twelve proposals to help enhance the provision of services for socially-isolated older men.

\section{1: Increase the capacity of voluntary and community organisations in relation to funding and governance issues}

Funding, sustainability and governance issues were of concern to all the organisations participating in this project, whether or not they were service funders or service providers. Complex bureaucratic processes may render it impossible for smaller organisations to apply for specific funding schemes. A report by Lloyds Bank Foundation for England and Wales (2015) highlighted the challenges faced by small and medium sized charities in England and Wales. These included an increasing demand for services due to welfare reform and demographic changes, alongside a decline in funding opportunities and complex commissioning processes. Thus, opportunities to increase capacity should be accessible to all groups. This is an issue that umbrella organisations such as the National Council for Voluntary Organisations (NCVO) and the Northern Ireland Council for Voluntary Action (NICVA) are trying to address. The legal requirement for charities to register with the Charity Commission in Northern Ireland is fairly recent (2013). Assistance to complete this registration is available from NICVA, the Charity Commission, and other organisations. However, smaller, community-based organisations may lack the staff or capacity to complete 
this process of registration. As a consequence of this, they are ineligible to apply for specific funding schemes.

\section{2: Participate in government consultations}

The social isolation of older men is relevant to several government strategies, such as those related to ageing, gender, health and social care. One key point emerging from the literature review was the negative effect of structural factors such as income, transport problems, and the ability of older people to maintain their existing relationships and participate fully in society (Buffel, Rémillard-Boilard and Phillipson, 2015). These macro-level issues cannot necessarily be resolved at a local level, and in many cases, need government intervention, which is difficult in a time of austerity and welfare reform.

Thus, it is important that organisations and individuals concerned with the social isolation of older men participate in consultation exercises to shape government policies and strategies. However, the ability of smaller organisations to participate in such consultations is limited due to lack of expertise or resources. The ability to influence a strategy or policy will therefore be skewed towards those larger organisations or sectors with more resources and capacity.

\section{3: Join relevant networks}

Responding to government and other consultations can be undertaken as an individual, organisation or part of a network. The lack of capacity of smaller organisations may be overcome by involvement with relevant networks. One such structure is the Men's Health Forum of Ireland (www.mhfi.org), and there are a number of other local, national and international fora and networks.

A particular issue of concern to the Men's Health Forum in Ireland is the lack of a Men's Health Strategy in Northern Ireland. Such a document would provide a practice and evaluative framework for those who commission services for men, as well as legitimacy and a policy imperative. One useful comparator is the United Nations Convention on the Elimination of Discrimination Against Women (CEDAW), which provides a useful policy framework for work within the women's sector.

Richardson and Smith (2011) discuss the development and implementation of national men's health strategies in Ireland and Australia. In particular, they highlight an increasing concern about sex differences in health status between men and women; a growing awareness of the need for more gender-specific approaches to health policy; and an expanding men's health field at a research, advocacy and community or voluntary level. Given the benefits to mental and physical health of services for socially-isolated older men, such a strategy could be of benefit to older men elsewhere.

Sector-led networks relevant to older people more generally may be a useful way to engage with politicians. Such fora also provide a critical mass to highlight structural issues with a range of stakeholders, such as transport providers, housing policy makers, and planning authorities.

\section{4: Develop a clear and up to date directory of services for statutory and third sectors}

The difficulty in finding out clear and current information about relevant services was highlighted throughout this project. Among statutory services, there is an emphasis on promoting and optimising independent functioning rather than resolving health issues $(\mathrm{DH}$, 
2008). For such reablement to be effective, there needs to be a focus on meeting people's social needs, which are often central to their perception of independence. Reablement services have an important role to play in accumulating and sharing good local knowledge about activities, clubs, groups and transport services (SCIE, 2012). Obviously, this necessitates an up-to-date directory of available services which can be accessed by professional staff and community members. Collaboration with key agencies is central in this process; as is the availability of this information in different formats and locations. Leaflets can quickly go out of date. An online directory could provide links to and from statutory and community websites, and be easily updated. Our experience of undertaking such a mapping exercise showed how extensive, and often difficult, a task this would be. Nevertheless, as well as providing an important signposting function, such a directory may help identify the overlap and duplication in services, which was highlighted during the interviews.

\section{5: Involve and train health and social care professionals}

The interviews with older men highlighted the importance of word-of-mouth as a mechanism for recruiting older men. However, this precludes the engagement of those men who are more socially isolated. In this context, health and social care professionals (such as GPs, Social Workers, and Community Mental Health practitioners) can be useful gatekeepers or information providers. . Advising these professionals of the need to be aware of the mental and physical health needs of socially-isolated older men is crucial, as is providing them with information about services. Whilst GPs play a significant role because they often know about the different aspect to a patient's life, one major restraint is the short amount of time that they have for face-to-face contact with patients. In addition, the reluctance of many men to visit their GP or other medical services, which is related to masculinity ideologies, norms and gender roles (Addis and Mahalik, 2003), remains a prohibitive factor.

\section{6: Think about how to engage with men}

Socially-isolated older men are a hidden population, and are often overlooked. Identifying these men and addressing their complex needs is a major challenge. The perceptions of older men interviewed in this study provided insights into how best to engage this group.

Firstly, there is a need to undertake outreach work, and to build up one-to-one relationships with men. This is important for men who are more socially-isolated, as they may be unwilling to accept that they need support and may not respond directly to information and publicity campaigns (Beach and Bamford, 2014). Moreover, older men may not necessarily perceive themselves as 'older', thus, services that explicitly target older people can be a deterrent to them.

In reference to the exceptional nature of Northern Irish society (see Recommendation 8), sectarianism remains an issue (Campbell, 2007). Individuals seeking services may experience anxiety around who can be trusted, making the task of engaging in services more difficult (DHSS, 2002). Thus, the importance of building up one-to-one trusting relationships at the point of referral is crucial in the Northern Irish context. In addition, in order to encourage ongoing attendance, each group needs a motivational leader, who has the skills to keep the group going.

These findings are supported by Johal, Suparov and Norman (2012), who highlight key themes for engaging with men, and Fowler (2012), who provides The Engagement Jigsaw - a 12 Point Plan for Effectively Engaging with Men. The literature also highlights specific needs of isolated older men, and one often forgotten group is carers. Data from ELSA suggest that 
nearly $15 \%$ of men aged 85 years or over were carers, and these men were more likely to be lonely than those who were not (Beach and Bamford, 2014). However, van den Hoonaard, Bennett and Evans (2014) contend that care-giving and widowhood represent feminised spaces that may present challenges for older men and masculine identity. Other marginalised groups include ethnic minority elders, LGBT communities, those in care homes, and refugees (Buffel, Rémillard-Boilard and Phillipson, 2015).

\section{7: Consider inter-generational work}

Most of the services that have been highlighted in this report are specifically targeted at older people. However, a more inter-generational approach may also be appropriate, or preferable, for some men. Indeed, this was highlighted by one of our interviewees, who said that he would be keen to encourage some crossover work with younger groups to widen the social circles provided by his group. Within some intergenerational practice, the focus is the development of intergenerational relationships, and the group's activities are the means to that end. For other groups, the activities are equally important, as with the intergenerational learning programmes highlighted by Golding and Foley (2017). It may also be that intergenerational projects provide an opportunity for social engagement by people who do not consider themselves 'old', or who do not wish to limit their social network according to age group. Gray et al. (2014) highlight the potential and challenges involved in undertaking intergenerational work to address a range of social problems.

\section{8: Recognise the legacy of the conflict}

The legacy of the conflict was acknowledged within several of the interviews, and this is an issue that is specific to Northern Ireland. It is often the case that groups can be dominated by one ethno-religious tradition, meaning that there can be difficulties among those with different realities (Murray and Murtagh, 2003). Thus, for some men that we talked to, discussing issues related to the conflict caused some tension within their organisations, whilst one interviewee felt that the service provided a comfortable place to address them. Thus, service providers should consider whether they want their environment to be 'neutral' (where discussion and symbolism are discouraged), or 'shared' (where all opinions can be openly discussed and respected). The approach taken will depend on the aims, ethos, and skills of individual organisations, facilitators and members.

\section{9: Acknowledge diversity of men}

One of the key issues for engaging with men is to recognise that not all men are the same (Fowler, 2012). The potential members of any service are likely to differ in terms of sex, age, socio-economic group, ethnicity, sexual orientation, mobility, where they live, and a range of other characteristics. Within Northern Ireland, consideration must also be given to the ethnoreligious traditions of men. Moreover, services targeted at men over 50 years could potentially include men who are nearly twice as old as others.

Thus, services should offer an environment and resources that acknowledges such diversity, for example, as noted in Recommendation 8, decisions need to be made around the promotion of an ethno-religious neutral or shared environment. Where appropriate, literature should be made available in different languages and formats, and consideration given to the physical environment of service provision. In particular, there is a need to be responsive, and sensitive, to the needs of men who are living on their own, whether due to widowhood, or other reasons. 


\section{0: Think about the range and type of activities that are offered}

Fowler (2012) suggests that for many men, services need to have a focus on an activity and a reason to be there. Furthermore, many men (at least in the early stages of engagement) seem to respond better to programmes which are task-orientated and which meet an immediate and tangible need. Thus, service providers should think about the range of activities that they are offering, and whether they are likely to appeal to their target audience.

The literature reviewed within the project incorporated interventions to redress social isolation, and a number of common themes focussed on the type and range of activities which should be on offer for socially-isolated men.

Firstly, interventions need to be delivered within a culture of caring - a welcoming and warm, comfortable environment. In the informant interviews in this study, the atmosphere of the men's clubs was a key factor in attracting and maintaining men. In many ways this was as important as the type and range of activities.

Secondly, programmes should be socially and culturally appropriate. This point is highlighted in The Engagement Jigsaw (Fowler, 2012), which highlights the need to create activities which are 'normal', mainstream and important. The informant interviews supported these views: men described the need for a range of action-based activities; activities which were viewed as 'masculine', which built on prior hobbies and helped develop new skills. Engaging in active tasks enabled many men to discuss thoughts and feelings, as one participant said 'You talk to people easier when you're doing something, especially men'. This may explain the success of initiatives such as Men's Sheds. These are grassroots community spaces for men which provide the opportunity to socialise and 'do stuff' in productive and health-giving ways (Golding, 2015), thus addressing social isolation and loneliness (Milligan et al., 2016). This resonates with the findings outlined by Beach and Bamford (2014), who found that men may prefer services which are built around their particular interests, workplace or experiences, such as football, or service in the armed forces.

Thirdly, activities should have meaning and purpose. Johal, Suparov and Norman (2012) identified that men avoid help-seeking behaviours; instead, activities which contribute to the needs of others in the community are important. The men in these interviews took pleasure in sharing their own practical skills and hobbies with others. Volunteering to help others and using activities to keep an active mind were also highly regarded. Activities such as cooking and practical means of improving lifestyle were valued, and can also be a significant help for men who find themselves living alone. Indeed, Kneale (2012) recommends the development of a widowhood strategy, that is, a specific set of strategies and policies to help older people adjust to the loss of a partner. Beach and Bamford (2014) highlight that older men tend to prefer services that reflect their longstanding interests and passions, and suggest that this may be why gender-neutral programmes feel 'feminised' to them. This may be due to the specific activities which may seem more suited to women, or that many third-sector organisations are run and staffed by women, so older men may have difficulties connecting with them. Furthermore, some of the respondents within Beach and Bamford's research felt that female service users did not always welcome the arrival of men.

However, it should be noted that some men lack confidence in taking part in activities which are unfamiliar. A non-threatening environment is crucial; men don't want to feel 'useless'. Finally, these suggestions are offered in the knowledge that men are not all the same and different activities will suit different men and at different stages of ageing. 


\section{1: Consider if men-only services are the most appropriate}

This review of services has tended to focus on activities that are for men only. One of the older interviewees within the project felt that having a group of men of a similar age and background can put men at ease to discuss personal problems, about ageing, retirement or health. For some men however, the interaction with both men and women is important, or at least, it does not cause them a significant problem, provided the activity is enjoyable and provides social contact.

One of the key stakeholders interviewed argued that providing men-only services was an equality issue, and so the focus of their organisation was on older people in general. However, this approach in itself can be criticised on equality grounds.

\section{2: Evaluate what works}

Whilst a wide variety of programmes and services have been introduced to help prevent or alleviate social isolation, there is little evidence about the types of programmes that are successful (Buffel, Rémillard-Boilard and Phillipson, 2015). It is important from the outset that systems are in place to evaluate the effectiveness of the service provided. Whilst formal systems of evaluation, such as those required by funders or regulation authorities, may be required, it is important that these are more than tick box exercises. Thought should be given to hearing the views of the men who attend the service, and the views of staff within the organisations. It is important to move evaluations beyond the 'happy sheet'; to consult with men in the design of the programme, check regularly with men if the programme is meeting their needs, as well as remaining cognisant of the changing needs of the group and of the community.

\section{Discussion}

This project explored the existing provision of services for older men, and suggested a range of actions that can help address the social isolation of this marginalised group. It is important to acknowledge that an evaluation of the extent and impact of services for isolated older men, can be critiqued for perpetuating a narrow and reductionist approach to the needs of this group (Lenette and Ingamells, 2015). Whilst responding to unmet need in the form of service provision may be seen as one dimension of community development, such professionalised interventions are limited. A community development approach which encourages the building of 'kinds of communities that have intent, capacity and capability to include and enable people across various stages of their life journeys (ibid.), would arguably offer more sustainable, interdependent and locality based responses.

Many of the themes within the literature (for example, Beach and Bamford, 2014; Buffel et al., 2015) match those identified within this research project. These similarities reinforce the need for organisations to learn from each other, as the same challenges are being faced elsewhere. However, other issues are pertinent to the local context. Firstly, consideration must be given to the exceptional nature of the Northern Irish ethno-religious conflict (Karari et al., 2013), and related segregation (Murray and Murtagh, 2003). The legacy of the conflict is considered long term in its impact and will continue to have an adverse effect on the populations' mental health (Wilson et al., 2015). Often communities and community resources are divided up in ways that maintain religious identity and claims to territory and space (Leonard, 2010; Murray and Murtagh, 2003). The men in this study offered variable responses to these issues; some felt tensions when talking about the conflict, whilst others 
felt it safe to do so. Perhaps this suggests that such services could act as potential mediators for societal change (Hughes et al., 2007).

Further research is needed on service development in this post-conflict society. The recommendations from this study suggest that organisations, their facilitators and members need to be explicit in considering how to engage men and how to promote a safe and shared environment in this context.

Secondly, this project was undertaken in an urban setting, however, the experience of life, and loneliness differs in urban (Scharf, 2011) compared to rural locations (Burholt, 2011). Thirdly, the project involved the participation of men living in the community, and those who were already availing of services. By definition, this excluded specific sub-groups which are known to experience limited intervention (Beach and Bamford, 2014). These include men living in residential settings; men with dementia; men within the LGBT community, in addition to the oldest old; and black and minority ethnic groups. Finally, it should be acknowledged that other communities have their own specific issues and complexities, perhaps related to ethnicity, social class or religion.

With an ageing population, acute loneliness and social isolation are major challenges facing our society. These can impact significantly on wellbeing and quality of life, with demonstrable negative health effects. At an individual level, by intervening in respect to social isolation, older men's quality of life can be improved. At a macro level, such interventions can relieve pressure on health and social care services and the cost of services. However, there is no single 'quick fix'. Instead, there needs to be a sustained, flexible and creative multi-sectoral approach, with direct input from older men and communities.

\section{Funding}

This project was commissioned by The Men's Working Group (a consortium of organisations within Belfast), with funding obtained from the Public Health Agency (NI). 


\section{References}

Addis, M. E. and Mahalik, J. R. (2003) Men, Masculinity, and the Contexts of Help Seeking', American Psychologist, 58, 5-14.

Arber, S., Davidson, K. and Ginn, J. (2003) Changing approaches to gender and later life, in S. Arber, K. Davidson and J. Ginn, eds, Gender and Ageing: Changing Roles and Relationships, Open University Press, Maidenhead, pp. 1-14.

Beach, Brian and Bamford, Sally-Marie (2014) Isolation: The emerging crisis for older men A report exploring experiences of social isolation and loneliness among older men in England, Independent Age, London.

Buffel, T., Rémillard-Boilard, S. and Phillipson, C. (2015) Social isolation among older people in urban areas. A review of the literature for the Ambition for Ageing programme in Greater Manchester, University of Manchester Institute for Collaborative Research on Ageing, Manchester.

Burholt, V. (2011) Loneliness of older men and women in rural areas of the UK, in Campaign to End Loneliness Safeguarding the Convoy. A call to action from the Campaign to End Loneliness, AgeUK, Abindgon, pp. 35-39.

Calasanti, T. (2004) Feminist gerontology and old men', Journal of Gerontology: Social Sciences, 59, 305-314.

Calasanti, T. (2003) Masculinities and care work in old age', in S. Arber, K. Davidson and J. Ginn, eds, Gender and Ageing: Changing Roles and Relationships, Open University Press, Abingdon, pp. 15-30.

Campbell, J. (2007). Social work, political violence and historical change: Reflections from Northern Ireland. Social Work \& Society, 5(3), 164-172.

Cordier, R. and Wilson, N. J. (2014) Community-based Men's Sheds: promoting male health, wellbeing and social inclusion in an international context, Health Promotion, 29, 483-93.

Courtenay, W. H. (2000) Constructions of masculinity and their influence on men's well-being: a theory of gender and health, Social Science and Medicine, 50, 1385-1401.

Dalgard, O. S., Dowrick, C., Lehtinen, V. et al. (2006) Negative life events, social support and gender difference in Depression. A multinational community survey with data from the ODIN study, Social Psychiatry and Psychiatric Epidemiology, 41, 444-451.

Davidson, K., Daly, T. and Arber, S. (2003) Exploring the social worlds of older men, in S. Arber, K. Davidson and J. Ginn, eds, Gender and Ageing: Changing Roles and Relationships, Open University Press, Abingdon, pp. 168-185.

De Jong Gierveld, J. (2003) Social networks and social well-being of older men and women living alone, in S. Arber, K. Davidson and J. Ginn, eds, Gender and Ageing: Changing Roles and Relationships, Open University Press, Abingdon, pp. 95-110.

Department of Health [DH] (2008) Making a strategic shift towards prevention and early intervention: key messages for decision makers, Department of Health (DH), London. 
Devine, P., Carter Anand, J., Montgomery, L. et al. (2014) A review of service provision for men aged 50+ (Belfast), Belfast: Volunteer Now

Dillon, B. and Butler, P. (2011) Facing the Challenge. The Impact of Recession and Unemployment on Men's Health in Ireland, Institute of Public Health in Ireland, Dublin/Belfast.

Emejulu, A. (2011) Re-theorizing feminist community development: towards a radical democratic citizenship, Community Development Journal, 46, 378-390.

Eng, P. M, Rimm, E. C, Fitzmaurice, G. et al. (2002) Social Ties and Change in Social Ties in Relation to Subsequent Total and Cause-specific Mortality and Coronary Heart Disease Incidence in Men, American Journal of Epidemiology, 155, 700-9.

Fay, M., Morrissey, M and Smyth, M. (1999) Northern Ireland's troubles: the human costs, Pluto Press, Dublin.

Fowler, C. (2012) The Engagement Jigsaw: A 12 Point plan for Effectively Engaging with Men, Men's Health Forum in Ireland, Belfast/Dublin.

Gray, A. M., Devine, P., Titterington, V. et al. (2014) Collaborating Towards an Age-Friendly Northern Ireland, ARK, Belfast.

Golding, B. (2015) Men Learning Through Life (and Men's Sheds), Adult Learning, 26, 170172.

Golding, B. and Foley, A. (2017) 'Men and Boys: Sharing the Skills Across Generations', Journal of Intergenerational Relationships, 15, 52-63.

Grimshaw, L. (2011) Community work as women's work? The gendering of English neighbourhood partnerships, Community Development Journal, 46, 3, 327-340.

Hughes, J., Campbell, A., Hewstone, M., \& Cairns, E. (2007). Segregation in Northern Ireland: implications for community relations policy. Policy Studies, 28(1), 33-53.

Johal, A., Supanov, A. and Norman, W. (2012) Invisible Men: engaging more men in social projects report, The Young Foundation, London.

Karari, P., Byrne, S., Skarlano, O. et al. (2013) The role of external economic assistance in nurturing cross-community contact and reconciliation in Northern Ireland and the Border Counties, Community Development Journal, 48, 587-604.

Kneale, D. (2012) Is Social Exclusion still important for Older People?, International Longevity Centre-UK, London

Leonard, M. (2010), 'Teenagers' Perceptions of Belfast as a Divided/Shared City', Shared Space, 10, 23-39.

Lenette, C. and Ingamells, A. (2015). Mind the Gap! The growing chasm between fundingdriven agencies, and social and community knowledge and practice, Community

Development Journal, 50, 88-103. 
Lloyds Bank Foundation for England and Wales (2015) Expert Yet Undervalued and On the Frontline. The views and voices of small and medium sized charities, Lloyds Bank Foundation for England and Wales, London.

Milligan, C., Neary, D., Payne, S. et al. (2016) Older men and social activity: a scoping review of Men's Sheds and other gendered interventions, Ageing and Society,36, 895-923.

Murray, M. and Murtagh, B. (2003) Exploring equity, diversity and interdependence through dialogue and understanding in rural Northern Ireland, Community Development Journal, 38, 287-297.

ONS (2015) Estimates of the Very Old (including Centenarians), England and Wales, and United Kingdom, 2002 to 2014, Office for National Statistics (ONS), London.

ONS (2014) Annual Mid-year Population Estimates, 2014, ONS, London.

ONS (2013) What does the 2011 Census tell us about the "oldest old" living in England \& Wales?, ONS, London.

Richardson, N. and Smith, J. A. (2011) National men's health policies in Ireland and Australia: what are the challenges associated with transitioning from development to implementation?, Public Health, 125, 424-32.

Ruxton, S. (2006) Working with older men: A review of Age Concern services, Age Concern Reports, London.

Scharf, T. (2011) 'Loneliness: an urban perspective', in Campaign to End Loneliness Safeguarding the Convoy. A call to action from the Campaign to End Loneliness, AgeUK, Abingdon, pp. 31-34.

SCIE (2012) At a Glance Briefing 60: Preventing loneliness and social isolation among older people, Social Care Institute for Excellence (SCIE), London.

Shuttleworth, I. and Lloyd, C. (2013) 'Moving apart or moving together? A snapshot of residential segregation from the 2011 Census', Shared Space, 16, 57-70.

Steptoe, A., Shankar, A., Demakakos, P. et al. (2013) Social isolation, loneliness, and allcause mortality in older men and women, Proceedings of the National Academy of Sciences of the United States of America, 110, 5797-5801.

Thompson, E. H. (2006) Images of old men's masculinity: Still a man?, Sex Roles, 55, 633648.

Thompson, E. H. and Whearty, P. M. (2004) Older men's social participation: the importance of masculine ideology, Journal of Men's Studies, 13, 5-24.

van den Hoonaard, D. K., Bennett, K. M. and Evans, E. (2014) 'I was there when she passed': older widowers' narratives of the death of their wife, Ageing and Society, 34, 974-991.

Wilson, G., Montgomery, L., Houston, S.;et al. (2015) Regress? React? Resolve?: An evaluation of mental health service provision in Northern Ireland, Action Mental Health, Belfast. 